\title{
DAS VARANDAS DE UNDER THE FRANGIPANI, MIA COUTO, FRANCISCO VARELA ET AL.
}

\author{
Paula Gândara \\ (Miami University)
}

\section{RESUMO}

Mia Couto é um caso aparte entre os escritores da Africa Lusófona. O mundo mais ou menos onírico/fantástico em que se movem as suas personagens constitui-se como um apelo ao uso do ponto de vista da física quântica par a par com as abordagens mais tradicionais ao texto literário. $\mathrm{O}$ objectivo deste estudo prende-se com a tentativa de alargar o escopo de leitura dos interessados em literatura africana no sentido de aproximar duas culturas, a africana e a ocidental, separadas por tradições epistemológicas muitas vezes difíceis de conciliar.

PALAVRAS-CHAVE: Mia Couto; física quântica; escritores da África Lusófona.

\begin{abstract}
Mia Couto is considered a special case in the field of African Lusophone writers due to the quality of his writing. His texts are imbedded of a magical, mythical world that nevertheless depicts the reality of Lusophone Africa. These characteristics together with the exceptional character of the themes on which he focuses constitute an invitation to apply to his works the concepts derived from quantum physics and the science of cognition. In this article I bring together two different structures of thought, Western and African, in an effort to give Western readers the tools to go beyond the basic approches to Couto's text.
\end{abstract}

KEYWORDS: Mia Couto; quantum physics African Lusophone writers. 
... [I]t is only the story that can continue beyond the war and the warrior. It is the story that outlives the sound of war-drums and the exploits of brave fighters. It is the story...that saves our progeny from blundering like blind beggars into the spikes of the cactus fence. The story is our escort; without it, we are blind. Does the blind man own his escort? No, neither do we the story; rather it is the story that owns us and directs us.

Chinua Achebe, Anthills of the Savannah (1987)

Eu já não acredito na vida, inspector. As coisas só fingem acontecer. Excelêncio morreu? Ou simplesmente mutou-se, deixou de se ver?

Mia Couto. A Varanda do Frangipani (1991)

A Varanda do Frangipani, de Mia Couto, será neste estudo o centro de uma análise que pretende ressaltar a diferença de entendimento da mesma obra face a Under the Frangipani ${ }^{1}$, dado que a tradução deste texto representa de uma forma palpável a diferença evidente entre a cultura tradicional africana e a ocidental. A obra oferece ao leitor uma série de possibilidades de análise, porém, quando lida em tradução, por sujeitos em processo de aprendizagem sobre as culturas africanas lusófonas, apresenta-se, em todos os casos que tive oportunidade de observar, como uma ficção de mistério, próxima duma história de detectives. De molde a transmitir a pluralidade significativa imensa de Under the Frangipani, ligaremos a tradição africana ao pensamento contemporâneo da área das ciências cognitivas, especificamente através de alguns princípios da física quântica² ${ }^{2} \mathrm{O}$ objectivo é o de criar pontos de contacto entre o pensamento ocidental e uma cultura onde impera a tradição oral, uma lógica de pensamento não-linear, a falta de fronteiras entre os mundos espiritual e material e, finalmente, a escrita de Mia Couto per si. De modo geral, pretendo criar modos alternativos de leitura de forma a evitar a alienação entre dois espaços culturais tão diferentes em coexistência na tradução de $A$ Varanda do Frangipani. Este ensaio mais não é do que uma tentativa de integrar a rígida estrutura do pensamento lógico ocidental e a lição africana do que é descrever a realidade que nos rodeia. A verdade é que ler Under the Frangipani e explicar a obra sem referências a uma língua portuguesa que se ultrapassa e recria no mundo linguístico de Mia Couto e no onírico moçambicano era um desafio que parecia perdido e condenado a pouco mais do que um determinado número de conclusões perceptíveis aos leitores em causa ${ }^{3}$.

Como se saberá Under the Frangipani começa por nos apresentar Ermelindo, uma personagem que nos fala depois da morte. Por não ter sido enterrado de acordo com a tradição, aliado à possibilidade de vir a ser levantado do túmulo por motivos de uma sociedade que precisa de um herói, custe o que custar, Ermelindo procura os conselhos de um "halavakuma”, que, de um modo prosaico, em tudo revelador da incapacidade de fazer sentido de uma cultura, é, em Under the Frangipani simplesmente um "armadillo", como se um papa-formigas pudesse condensar, de algum 
modo, a significação de "halavakuma" . Conclui a personagem a favor de tais conselhos decidindo reincarnar no corpo de Izidine, um detective cuja morte se prevê para seis dias depois e através da qual Ermelindo pensa redimir as circunstâncias do seu próprio enterro.

Izidine, por si só, encontra-se alienado da sua própria cultura, no entanto, ao deparar com uma comunidade de idosos que subvertem todas as regras de uma investigação policial clamando cada um deles confissões não requisitadas de uma morte que acontece em espaços e tempos diferentes para cada um dos participantes, Izidine vê-se confrontado até ao limite com as mesmas questões de um qualquer leitor ocidental inexperiente face ao confronto com a tradição oral africana. Como é possível que todas estas pessoas se confessem culpadas do mesmo crime? Como é possível que todas as histórias se embrenhem em mundos mais ou menos esotéricos que mais lembram invenções desregradas que outra coisa qualquer?

Vamos então partir do princípio que um dos modos de diferença mais intransponíveis entre as duas culturas reside no modo de contar uma história/estória. Na tradição oral africana a estória é passada de forma grupal de geração em geração, ou seja, a estória que se partilha é contada por várias pessoas e está aberta à inserção de novos momentos e detalhes. Brevemente, pode-se dizer que o que também é chamado de oratura africana é essencialmente uma experiência comunitária. Nas sociedades africanas tradicionais, todos participam do contar da estória (e manter-se-á a diferença de grafia para ressalvar o carácter da estória oral face à história escrita), quer seja em cerimonial ou não, transformando-o numa experiência oral interactiva. Trata-se de uma situação que podemos denominar de pergunta-resposta em que o solista (o narrador principal) levanta a questão/canção a que a comunidade responde a intervalos regulares. Muitas das vezes, estes contadores de estórias são profissionais, sujeitos a treinos de memória, música e técnicas verbais, mas também a treinos de dimensão espiritual e ética que se acreditam ser fundamentais para o controle das forças ocultas e das energias primais desencadeadas pelo contar/cantar da estória:

E lhe contei sobre a origem do antigamente. Primeiro, o mundo era feito só de homens. Não havia àrvores, nem animais, nem pedras. Só existiam homens. Contudo, nasciam tantos seres humanos que os deuses viram que eram de mais e demasiado iguais. Então, decidiram transformar alguns homens em plantas, outros em bichos. E ainda outros em pedras. Resultado? Somos irmãos, àrvores e bichos, bichos e homens, homens e pedras. Somos todos parentes saídos da mesma matéria. (COUTO, 1991, p. 69)

Este poder de criação/destruição do mundo através da palavra é algo praticamente ausente da sociedade ocidental (cf. MUTERE, "African Oral Aesthetic"). Na cultura ocidental, a história é de natureza cursiva, espartilhada pelo signo linguístico que define a natureza fixa e restrita de partilhar a informação naquele que é o lugar da escrita. Estes dois modos 
de entender o mundo e passar a informação acabam inevitavelmente por condicionar o modo como ambas as sociedades tendem a perceber a realidade ao seu redor e, se a última se encontra obrigada ao ênfase numa \verdade $\bigotimes$ e na realidade factual, a primeira espraiou as suas possibilidades de entendimento do mundo para além da factualidade do verbo grifado, usando a narrativa, as adivinhas, os provérbios e a canção numa oratura de objectivos éticos, pedagógicos e de simples entretenimento: “Começou, então, a entoar em surdina uma antiga canção de embalar. Izidine foi levado para longe, para fora do acontecível." (COUTO, 1991, p. 45). A canção, tal como a estória, serve para que a audiência se possa ausentar da realidade concreta para alcançar um outro espaço de vivência, indisponível a quem não tem como alcançar os princípios da tradição ou o Princípio da Incerteza $\bigotimes$ a que voltaremos muito em breve. É então necessário reclamar pelo menos dois momentos fundamentais do espaço epistemológico ocidental para a possível explicação-alteração das perspectivas de entendimento de Under the Frangipani. O primeiro surge da ideia da morte do autor e do grau zero da escrita. Estas teorias, que têm apontado, entre outras coisas, para as limitações do texto escrito, deixaram claro que a palavra escrita é o espaço ideal para a perda do sujeito. Na verdade, a palavra escrita constitui-se como uma realidade de tipo negativo em que a identidade do autor e do próprio corpo da escrita se apresentam de forma neutra e por isso mesmo oblíqua quanto ao modo como a comunicação se processa entre o "morto" autor e o mais ou menos mecânico leitor subjugado por teorias estruturalistas ou perdido na pluralidade inconsequente das possíveis leituras pós-modernistas. Aceitando esta possibilidade teórica, torna-se desde já mais fácil de aceitar um modo alternativo de percepcionar a realidade. Se o autor está morto e/ou se a pluralidade de leituras pós-modernistas impelem à sua autoanulação o leitor pode mais facilmente abrir-se a uma possibilidade de relativismo. A verdade é que a questão da percepção engloba diversos ângulos, o científico, o matemático e, obviamente, o filosófico. Do ponto de vista da matemática, esta interessa-nos apenas como o ponto de vista matemático da percepção, ou seja, como reconhecer categorias, definições. Iremos debruçar-nos sobre esta notação apenas com o intuito de estabelecer uma sequência lógica de elementos que possam facilitar o entendimento do ponto de vista filosófico-científico da ciência cognitiva. Assim defina-se "espaço". O espaço a que aqui nos remetemos, da ordem do exemplo, será referido como E, e pode ser tão geral quanto se queira. Ou seja, em E podemos organizar conjuntos de items ou ideias derivados desse mesmo espaço e relacionados entre si; assim por exemplo $\mathrm{E}=\{$ todos os gatos $\}$; ou mais específico $\mathrm{E}=\{$ todos os gatos brancos $\}$. Dentro deste conjunto poder-se-ia considerar $\mathrm{a}=\{$ todos os gatos brancos de olhos azuis $\}, \mathrm{b}=\{$ todos os gatos brancos que não têm olhos azuis\}. Aparentemente esta é uma definição, ou uma categorização simples, no entanto, tanto o conceito de "branco" como o de "azul" são relativos. Numa lógica relativa o que acontece é que o conjunto se define pelo grau de conexão de cada elemento (a) em relação a E. Ora, este grau de conexão é determinado por uma série de re- 
gras pré-estabelecidas, sejam elas línguisticas, matemáticas ou outras quaisquer. Mas, para além deste elemento, o grau de conexão pode também ser determinado com base na percepção do sujeito. Ou seja, assim que determinamos aquilo que é, aparentemente, um conjunto e subconjuntos definidos, descobrimos logo de seguida a existência de contradições na própria categorização. Vejamos agora o que acontece quando se determina a existência de dois estados opostos que existem simultaneamente. Temos uma situação em que inquirimos a duas pessoas (A e B) o que é um "bom salário" e um "mau salário". Os conjuntos de apreciação definir-se-iam normalmente, numa situação desta natureza, por cenários entre x e y, sendo x um bom salário e y o mau salário. A diz-nos que x é mais de 250.000 Euros e y é menos do que 250.000 Euros. B diz-nos que x é mais que 175.000 Euros e y é menos que 175.000 Euros. Agora, digamos que um determinado indivíduo ganha 200.000 Euros; isto é $=\mathrm{x},=\mathrm{y}$, ou ambos? Se a categorização fosse feita com base na pessoa A seria x, mas se fosse feita pela pessoa B já seria y, porém, de um ponto de vista geral, pode ser ambos. Se eu escolher a última hipótese, estou a apresentar uma contradição tanto a A quanto a $B$. Mesmo quando determino que o valor é relativo a $A$ e a $B$, não deixo de estar face a uma contradição. Como é que isto se relaciona com Mia Couto? $\mathrm{O}$ autor parece confirmar que uma categorização faz parte de um sentido de ordem: não só Ermelindo se rege por uma ordem fixa na apreciação dos elementos que se lhe apresentam como, por exemplo, Marta nos oferece uma categorização baseada nos momentos pré e pós guerra (cf. COUTO, 2001, p. 123). De seguida, quando descreve a discussão com Vasto introduz-se a noção de raça e do peso da mesma. Concebe ela depois, relacionando o assunto, uma categorização em que discerne a existência de dois estados simultaneamente: na verdade somos todos mulatos, só que em alguns casos isto é mais visível do que em outros (cf. COUTO, 2001, p. 128). Não só concebe a categoria de "mulato" como introduz a questão de percepção do sujeito através da "visibilidade", ou seja, a categorização não implica certeza e esta falta de certeza é facilmente classificável como uma questão moral e filosófica. Pontos que igualmente se levantam em Mia Couto: se todos os participantes se confessam culpados da morte de Vasto e se, portanto, todos mentem, não deveriam ser todos castigados pela mentira em que incorrem? No entanto, a questão da "mentira" é relativa à cultura em que se insere e, assim, se no mundo ocidental todos são mentirosos, no universo de Mia Couto todos dizem a verdade. A questão da física quântica vai assim desenvolver este conceito de incerteza de um modo filosófico e é a partir deste segundo momento na epistemologia ocidental que se constitui a nossa hipótese de leitura. Este momento nasce em 1920 quando De Broglie ${ }^{5}$ nos apresenta um novo paradigma: a mecânica newtoniana é substituida pela mecânica quântica, a teoria da relatividade é substituida pela relatividade da física quântica. O conceito que dá a Louis De Broglie o prémio Nobel é a chamada dualidade onda/partícula. De acordo com os estudos apresentados, a realidade não se define pela existência de uma partícula, mas sim de uma onda. A partícula de que nos apercebemos como 
constituinte da realidade não passa de uma partícula componente da onda de que faz parte. Imagine-se a onda que se cria num lago quando se atira uma pedra contra a sua superfície e alargue-se essa imagem à de um corpo físico. As partículas propagam-se como uma onda e este movimento cria uma zona de interferência entre os corpos que permite dizer sem pejo que os diversos corpos se encontram em ligação efectiva com o mundo que os rodeia. A linguagem parece infantil, mas o conceito é de tal maneira inovador e acarreta alterações tais no modo como inferimos o que se passa à nossa volta que na realidade passaram-se cerca de 90 anos desde que a teoria foi descoberta e ainda não faz parte do conhecimento comum. Assim, de forma muito concisa, diga-se que o trabalho iniciado por De Broglie vem a ser desenvolvido pelo austríaco Erwin Schrödinger. Este, em 1926, completa uma equação descritiva do comportamento ondular completo de uma partícula, em três dimensões. O resultado explica com grande precisão as propriedades "inconstantes" dos átomos em geral. De acordo com Schrödinger, não é possível determinar a trajetória de uma partícula. Uma conclusão que Werner Heisenberg ${ }^{6}$ já havia alcançado no seu Princípio da Incerteza e que nos ensinava que quanto maior a exactidão na determinação experimental da posição de um electrão, menor a exactidão na determinação da sua velocidade, e vice-versa. Como ambos são necessários para definir uma trajectória, a ideia de que seria possível determinar a posição de um electrão teria que ser descartada. Muitos físicos passaram a assumir que o electrão não estaria necessariamente em lugar nenhum, até que fosse detectado numa experimentação. As informações que podem ser obtidas dizem então da probabilidade de encontrar o electrão num determinado lugar, probabilidade esta que está relacionada com o chamado módulo da função de onda. A mecânica quântica vem assim introduzir um espaço de incerteza e subjectividade no reino da ciência que, como facilmente se pode imaginar, tem sido de difícil aceitação. Encontram-se, consequentemente, algumas teorias destinadas a explicar este lugar da incerteza. Entre elas mencionem-se as teorias das variáveis ocultas. Uma série de pesquisadores tem demonstrado, por meio de teoremas de álgebra, que para reproduzirem as predições quânticas estas teorias devem incorporar um traço conceitual inteiramente não-clássico, o chamado contextualismo, que significa que os valores das grandezas físicas podem reflectir não apenas as propriedades do objecto, mas também todo o seu "contexto". Um traço que leva ao desenvolvimento da ideia de que há um holismo, ou "totalidade" no mundo (cf. Margulis 1995). Outra das teorias que nos interessa aqui é a chamada Interpretação "ortodoxa" ou "de Copenhague" . Esta teoria incorpora uma complexidade de posições a que não podemos fazer justiça; porém, mencione-se uma das versões mais radicais que sustenta que, ao contrário de todas as demais teorias físicas, a mecânica quântica não tem como objectivo descrever nenhuma realidade transcendente aos fenómenos. A sua função seria apenas a de descrever e correlacionar formalmente os fenómenos que estuda. Trata-se de uma teoria que vê a mecânica quântica de um ponto de vista instrumental, destinada apenas à predição e ao cálculo. A ser assim, a teoria abdicaria da sua função explicativa. Outra versão da 
mesma teoria, porém, pende para a posição filosófica do idealismo. Neste caso, a teoria é entendida como que se referindo a uma realidade subjectiva, relativa ao papel do observador/cientista/sujeito actante da experiência em causa. Trata-se já não de "penso, logo existo", mas de "ser é percepcionar"8. Já se tinha referido este carácter não determinístico da física quântica: o Princípio da Incerteza postula esta incapacidade de determinar o resultado exacto de um estado posterior num sistema quântico (um átomo, por exemplo) a partir do seu estado inicial. Pode-se, no entanto, e como já sabemos, determinar a probabilidade de um resultado. Mas quem define o que estará sendo medido e qual o resultado é o observador. Levanta-se então, de modo agudo, a necessidade de entender o espaço cognitivo do observador e resvala-se de modo consistente para as ciências cognitivas. Torna-se cada vez mais evidente que tudo isto tem que ter um impacto consistente na explicação do que, no mundo de Mia Couto, aparece como uma série de inconsistências, senão mesmo contradições. O mundo verbal e ideológico de Couto fica sujeito a novas interpretações cientifico-filosóficas que contribuem para a aceitação da tradição oral africana pelo público ocidental, ainda profundamente limitado por uma percepção imediatista e uma compulsão à repetição freudiana que impede a criação e aceitação de realidades e percepções dinâmicas da realidade.

Finalmente, para a proposta que nos ocupa, interessa ainda apresentar uma outra teoria. Nesta, todas as propriedades que na posição anterior são dadas como meramente potenciais de facto existem simultaneamente: é a chamada teoria da Interpretação dos Muitos Mundos9. Uma teoria que, como já vimos, se pode contemplar do ponto de vista matemático. Aqui, porém, trata-se de confrontar a realidade de uma forma geral, e não uma determinada categorização. Para já, dificilmente se observa tal realidade - embora em muitos laboratórios nos Estados Unidos já seja possível fotografar o mesmo ponto em dois espaços simultaneamente - e sugere-se que cada um desses valores "existe" num mundo diferente. Haveria, pois, uma multiplicidade infinita de universos. O carácter definido das nossas observações dever-se-á ao facto de que nós próprios existimos em versões múltiplas e em cada uma dessas versões estamos associados a um conjunto definido de valores das grandezas físicas dos objectos com os quais interagimos. E, mais uma vez, vale a pena observar esta ideia em Mia Couto: "Ao menos, aqui na fortaleza, os velhos intentavam outra ordem na minha vivência. Eles me davam o ciclo dos sonhos." (COUTO, 1991, pp. 127-8). Trata-se da ideia de viver em duas ordens diferentes de realidade ao mesmo tempo, e de aceitar que uma é tão válida como a outra. Mais, o sujeito tem plena consciência de si e essa autoconsciência é fundamental para a aceitação dos vários mundos em coexistência em que a consciência se vê outra:

Houve tempo que a cidade ainda me tentou. E ainda ensaiei me instalar por aquelas bandas. Mas eu lá adoecia de um mal que não tem nome. Era como se desaprendesse as mais naturais funções: escutar, olhar, respirar. (COUTO, 1991, p. 128) 
Veja-se como a percepção envolve precisamente essas funções e define a capacidade De o observador se colocar em posição introspectiva. Escutar, olhar e respirar fazem parte de uma estrutura temporal ligada ao passado e em extensão para o futuro. Como nos diz Marta: "[e]u me degradava a custo de sexo, bebida e seringa. Nem queria saber de futuros. Me interessava apenas o instantâneo momento." (COUTO, 1991, p. 130). É quando Marta se projecta para lá do momento e aceita o passado e o futuro através dos velhos do asilo que a vida se resolve pacificamente: "Tudo começa antes do antigamente. Nós dizemos ntumbuluko. Parece longe, mas é lá que nascem os dias que estão ainda em botão. A morte desse Excelêncio já começou antes dele nascer." (COUTO, 1991, p. 28)

Ou então:

O parto é uma mentira: nós não nascemos nele. Antes, já estamos nascendo. A gente vai acordando no antecedente tempo, antes mesmo de nascer. É como a planta que, no segredo da terra, já é raiz antes de proclamar seu verde sobre o mundo. (COUTO, 1991, p. 34)

Ou então:

A real [...] quantum state vector [...] issues from the present event and travels to the future event. The future event is then stimulated to send back through time an 'echo' of the state vector [...] toward the present event. [...] Awareness (mental events) arise as a result of the projection of the brain events into space and back in time to the loci of physical events. (WOLF in HAMEROFF, 1999, p. 360)

As perspectivas de estudo que se abrem face aos horizontes da física quântica indicam pelo menos que o modo positivista que tem presidido à organização e percepção da realidade ocidental é verificadamente limitado senão mesmo erróneo e que até mesmo a percepção linear do tempo é uma ilusão. Esta breve apresentação serve de modo basilar à interpretação de Under the Frangipani. À medida que Izidine vai interrogando os suspeitos, a sua confusão vai progressivamente aumentando, parece que todos mentem e que na verdade não se pode afiançar, sequer, a morte de Vasto Excelêncio, cujo corpo apenas se avista por quem "sabe/ aceita” que ele está morto, um corpo que logo depois desaparece, chegando-se ao lugar onde ninguém sabe se todos o mataram ou se simplesmente ele se transmutou:

O certo é que os do helicóptero deram com o corpo de Excelêncio esparramorto nas rochas da barreira. Viram-no quando o aparelho se aproximava da fortaleza.

Assim que pousaram, desceram a encosta para recuperar o corpo. Quando chegaram às rochas, porém, já não encontraram os restos de Excelêncio. Buscaram nas imediações. Em vão. O cadáver desaparecera misteriosamente. As ondas o levaram, assim pensaram. [...] 
Contudo, quando sobrevoavam a zona voltaram a deparar com o corpo estendido sobre os rochedos. Como voltara para ali? Estaria afinal, vivo? Impossível. (COUTO, 1991, pp. 23-4)

Aceitando a possibilidade relativista da física quântica alargada ao mundo dos corpos de percepção a olho nu, este corpo que aparece e desaparece inexplicavelmente passa a ser inteligível. O corpo existe num espaço relativo, definido pela percepção do observador, num mundo delimitado pela incerteza das probabilidades. Mais, o facto de todos se confessarem culpados da morte de Vasto passa a ser possível num mundo em que se admite a posssibilidade de existir em diversos espaços ao mesmo tempo. Se as probabilidades de algo acontecer mudam com o tempo e com o papel do observador vemo-nos num espaço em que as probabilidades matemáticas de medir a ocorrência de um determinado evento causam uma interrogação efectiva acerca do quando e do como de uma determinada realidade. Um dos exemplos mais comuns no reino científico para explicar o Príncipio da Incerteza é o do gato de Schrödinger ${ }^{10}$. O gato é fechado numa caixa onde se insere uma quantidade ínfima de uma partícula atómica que, a ser desencadeada, matará o gato. Após algum tempo observa-se a caixa para saber se o gato está ou não morto ${ }^{11}$. Para alguns cientistas, esta questão é, em si mesma, irrelevante; o gato só está morto a partir do momento que o observador detecta que o gato está morto já que até esse momento o sistema oscila na incerteza das probabilidades que só se definem numa determinada direcção quando o observador causa o colapso do sistema em direcção a uma possibilidade, agora detectada. No caso de Under the Frangipani a questão é se Vasto está ou não morto, dado que ninguém percepciona sua morte efectiva para além de um reino narrativo em que a estória pode ser o único elemento de criação da realidade. Mais, as diferentes mortes de Vasto, de acordo com os diversos actores podem facilmente ser um impecilho a que uma realidade se torne viável; se cada um percepciona uma realidade distinta, o sistema não colapsa nunca em relação a uma possibilidade efectiva, mas mantém-se no reino das probabilidades. Assim, levanta-se desde logo a crença no poder da palavra, sem a qual não há um morto e muito menos um corpo.

Sou um menino que envelheceu logo à nascença. Dizem que, por isso, me é proibido contar minha própria história. Quando terminar o relato eu estarei morto. [...] Mesmo assim me intento, faço na palavra o esconderijo do tempo. (COUTO, 1991, pp. 28-9)

Esta personagem congrega o poder da palavra face à sua própria vida, e é na verdade da palavra que a morte chega - se mentir, não morrerá. Mais uma vez é a percepção da realidade que determina o desenrolar dos eventos. Se a realidade se inventa, a morte não se desenha. Uma idéia, aliás, que subjaz à criação das Mil e Uma Noites, enquanto Scherazade inventar uma nova história a sua vida será poupada. Ou, por outras palavras, enquanto não se definir "o relato" não existe a possibilidade, existem as probabilidades em suspensão. 
Outro dos exemplos do Princípio da Incerteza, usado pela comunidade científica para que se possa entender a existência de um ponto em dois espaços simultaneamente, relata o modo como um berlinde revolve à volta de um prato e se encontra num estado de superposição, isto é, em dois sítios do prato ao mesmo tempo, e ainda rodando sobre si, paralelamente. É apenas quando se abana o prato, mesmo que ligeiramente, que o berlinde define a sua posição parando num ponto somente. O mesmo se pode dizer de Vasto, se todos o mataram e se nenhuma probabilidade se define na mente do observador, então Vasto não pode estar definitivamente aqui ou ali e o seu corpo não pode ser visto num determinado lugar, já que o observador, preso na rede de probabilidades, não tem como fazer um julgamento e obrigar ao chamado colapso do sistema.

É claro que fazer esta analogia do ponto de vista das distâncias atómicas para as distâncias perceptíveis a olho nu é profundamente arriscado do ponto de vista científico, mas não do ponto de vista filosófico que aqui nos é permitido como decorrência. A verdade é que, cientificamente, quando se aumentam as distâncias que separam dois electrões em superposição, a tendência é para o espaço circundante intervir muito mais rapidamente, causando o desmantelamento desse mesmo estado, ou seja, os electrões deixam de estar em superposição, em dois momentos simultaneamente, e define-se uma circunstância. No caso de Under the Frangipani muito embora não se tratem de distâncias atómicas ou sub-atómicas tratam-se de distâncias do nível do pensamento e da espiritualidade da cultura africana face à ocidental e de molde a explicar o sucedido a uma plateia ocidental parece-nos mais do que lícito fazer uso dos príncipios elementares da física quântica de modo a tornar verosímil aquilo que, para um leitor ocidental desavisado, é, à primeira vista, pura invenção. Ora, sem seguir os conselhos de Marta e aceitar a possibilidade paralela de tempos e espaços ou uma alternativa mais credível a quem se vê rodeado de factores positivistas, Under the Frangipani não poderá ultrapassar o espaço metafórico, ou, pior ainda, do romance policial: "Há que guardar este passado. Senão o país fica sem chão. - Eu aceito tudo, Marta. Quero saber apenas quem matou Vasto Excelêncio. Só isso." (COUTO, 1991, p. 103).

Quanto a Ermelindo, para que a leitura deste texto nos remeta para mais do que uma vaga ideia acerca da existência de uma espécie de fantasma cuja função - num contexto ocidental - mal se entende para além da recuperação de um tempo perdido onde, aliás, se integram os moradores do asilo, é-se, de novo, forçado a introduzir princípios da ordem das ciências cognitivas e da física quântica. Ermelindo, numa percepção inicial, não passa do reino do fantástico, quando como o morto assume a função de sujeito narrativo - "Sou o morto" (COUTO, 1991, p. 11): quem está vivo é Izidine, não Ermelindo. Ermelindo parece não ter outra função senão a de alertar o leitor para um tempo africano perdido para a sua própria sociedade - "Me faltou cerimónia e tradição quando me enterraram" (COUTO, 1991, p. 11). Primeiro, levantem-se então questões a que o pró- 
prio texto possa responder. Quem é a personagem principal, Ermelindo ou Izidine? De um ponto de vista metafórico não estará Izidine mais morto do que Ermelindo? As respostas estão dadas no texto e mais uma vez, se se integrar o carácter evolutivo da tradição oral africana com o modelo científico da física quântica e da ciência cognitiva, talvez se possam alcançar respostas menos esperadas e um pouco mais coerentes para os dois lados do Atlântico. Qualquer um dos sujeitos existe em espaços diferentes e tanto um como o outro têm a mesma relevância na criação da/s his/estória/s; simplesmente um existe no universo material em que estamos habituados a percepcionar a nossa existência, enquanto que o outro existe num universo alternativo a que, ainda, a grande maioria de nós não tem acesso:

Izidine [...] tinha um plano: entrevistaria, em cada noite, um dos velhos sobreviventes. De dia procederia a investigações no terreno. Depois de jantar, se sentaria junto à fogueira a escutar o testemunho de cada um. $\mathrm{Na}$ manhã seguinte anotaria tudo o que escutara na anterior noite. Assim surgiu um pequeno caderno de notas, este caderno com a letra do inspector fixando as falas dos mais velhos e que eu agora levo comigo para o fundo da minha sepultura. O livrinho apodrecerá com os meus restos. Os bichos se alimentarão dessas vozes antigas. (COUTO, 1991, pp. 25-6)

Como se pode ler, Izidine serve a ordem linear, o tempo histórico e a fixa ordem escrita. Ermelindo, não só encontra existência num espaço e num tempo alternativos como ainda se apropria da realidade palpável para lhe dar novo destino, onde, uma vez mais, a harmonia da voz e da terra ganha a primazia. Por outro lado, a existência de Ermelindo serve ainda à questão da essência do "eu” a que se voltará adiante.

$\mathrm{Na}$ tradição oral africana, a história passa de boca em boca e o contador da história vai integrando as perguntas da sua audiência no enredo. Do ponto de vista ocidental, e definitivamente do ponto de vista do estudioso (que o próprio Izidine personifica), esta incorporação de elementos corrói o carácter histórico dos eventos narrados. Do ponto de vista da física quântica, porém, cada um dos confessos poderia, de facto, ter cometido o crime nas realidades de/em que eles próprios são os sujeitos actantes. Mais, a física quântica especifica em experimentações efectivas que a mente tem a capacidade de alterar a realidade, ou seja, que o observador tem um papel activo sobre o fenómeno observado. Em Conscious Acts of Creation $^{12}$ se descreve uma série de experiências em que um grupo de pessoas em meditação altera ipsis factum o tempo larvar das moscas; o ph da água; o tempo de fervura de um líquido. Cientificamente, sabe-se hoje que o poder da mente do observador é crucial para o desenvolvimento do fenómeno observado. Do ponto de vista das ciências cognitivas - em que se integra a física quântica -, e mais especificamente da Teoria de Santiago (cf. MATURAN, 1980), só o observador define a realidade. E quem é o observador? Em The Embodied Mind, Francisco Varela define a possibilidade 
de encontrar o observador a partir do que ele chama os cinco agregados. Estes são formas, sentimentos/sensações, percepções, padrões de humor e consciência e nenhum deles determina afinal a existência de um "eu" mas apenas a de um observador que pode e deve auto-observar-se e auto-(re) construir-se. As formas referem-se ao corpo e ao ambiente que o rodeia e implicam os cinco sentidos bem como a mente - aqui sinónimo de pensamento. Na verdade, a concepção comum de que o nosso corpo físico ou de que o nosso pensamento nos define é uma concepção errônea, dado que se trata apenas de uma ou duas dimensões de uma complexidade que é o "eu" ou melhor, o "observador". Ermelindo, constituindo-se como pensamento no corpo de Izidine, serve assim à complexa questão acerca da viabilidade do "eu”. A concepção descartiana do "penso, logo existo" cai por terra já que evidentemente Ermelindo pensa e sente, mas nem por isso "existe" à semelhança de Izidine:

The point is not whether we can redefine the self in some way that makes us comfortable or intellectually satisfied, nor is it to determine whether there really is an absolute self that is nonetheless inacessible to us. The point is rather to develop mindfulness of an insight into our situation as we experience it here and now (VARELA, 1991, p. 72)

O segundo agregado, os sentimentos e as sensações, incorporadas em Izidine, por exemplo, quando se sente confuso perante a multiplicidade de respostas que lhe são oferecidas, fazem parte de uma possibilidade real que o observador pode facilmente alterar a partir do momento que questiona o cerne desse mesmo sentir, algo para o qual Marta o alerta várias vezes. Leia-se um excerto do diálogo entre Marta e o inspector:

The policeman smiled scornfully. Marta corrected his skepticism.

- Don't you realise how arrogant you are? [...]

$[\mathrm{T}]$ he inspector recalled the nurse's words. And he smiled. Could it be that Marta was right? [...] Separation had curtailed his knowledge of the culture, of the languages, of the little things that shape a people's soul. (COUTO, 2001, p. 38)

As percepções, o terceiro agregado, são, de novo, uma noção fluida conforme o estado do observador. Varela considera três estados que influenciam de forma fundamental o observador e logo o que é observado: a paixão/desejo, a agressão/zanga, a ilusão/o ignorar. Mais uma vez, Marta avisa Izidine do modo como a ignorância da cultura moçambicana o impede de comunicar com os habitantes do asilo:

- What am I supposed to do? Tell me, you who re familiar with this world...

- You want to punish them!

- I want to get to the truth...

- You want to punish them, and do you know why? Because 
you're scared of them!

- Scared, me?

- Yes, scared. These old people are the past you are trampling on deep inside your head. These old people remind you of where you come from...

Once again, fury got the better of him. (COUTO, 2001, pp. 72-3) (sic)

Seguem-se os padrões de humor, que se relacionam com a definição das nossas personalidades, tratam-se de padrões de pensamento, de sentimentos, de percepção e acção que repetindo-se ao longo das nossas vidas lhes dão um sentido de permanência, mas também de fatalismo. Quando Izidine se vê confrontado com a surpresa constante de cada momento, todos os padrões têm que ser desfeitos e uma nova realidade tem finalmente possibilidade de emergir. Por fim, a consciência. Este agregado engloba todos os outros. A experiência revela-se como algo intrínseco à consciência. Ou seja, a nossa experiência reflecte a nossa consciência. Uma noção que é igualmente parte da tradição oral africana dado que esta estabelece a existência de um passado e reconhece os diferentes graus de conhecimento face a uma determinada experiência. Todos estes agregados compõem o que Varela considera o "eu":

Este homem que estou ocupando é um tal Izidine Naíta [...]. Estou num canto de sua alma, espreito-lhe com cuidado para não atrapalhar os dentros dele. Porque este Izidine, agora, sou eu. Vou com ele, nou nele, vou ele. Falo com quem ele fala. Desejo quem ele deseja. Sonho quem ele sonha. (COUTO, 1991, p. 21)

Debrucemo-nos de novo sobre as características da tradição oral africana. Esta é, acima de tudo, um modo específico de entender o temp na sua variedade e multiplicidade. Multiplicidade é aquilo que de imediato ressalta de Under the Frangipani, multiplicidade de narrativas, de personagens, de explicações, de tempos e lugares - sem que nunca se saia do espaço do asilo, note-se. A multidimensionalidade do texto não termina aqui, mas estende-se à ambiguidade com que as personagens definem a sua própria estória como o contexto real a ter em conta. Do ponto de vista da tradição oral africana, cada uma das personagens pode assim ser a culpada sem que se considere a existência de uma história diferente, mas antes uma concepção quase única do que se pode considerar como sendo a verdade. $\mathrm{O}$ conceito de verdade ocidental não tem qualquer aplicação neste contexto. Ao longo da narrativa de Mia Couto, apercebemo-nos de que existem muitas verdades, tantas quantas as diferentes narrativas, nenhuma excluindo a existência de outra. O presente, o passado e o futuro não são uma realidade linear, mas uma criação da consciência de cada um.

A tradição oral africana reconhece a passagem do tempo através dos seus resultados visiveis sobre a realidade ao redor. Do mesmo modo, a física quântica ensina-nos que podemos criar o nosso próprio tempo e 
espaço ao assumirmos a existência dos cinco agregados e a necessidade de um observador que deles possa tomar consciência e sobre/com eles agir. Veja-se um exemplo desta qualidade em Under the Frangipani. Little Miss No/ Nãozinha será o exemplo ideal se pensarmos na contraparte das experiências efectuadas no reino da física quântica. The Hidden Messages in Water oferece-nos uma série de fotos das moléculas da água antes e depois de ter sido exposta a uma série de estímulos, desde a benção de um monge budista à manipulação por um sujeito agressivo. As moléculas da água alteram-se conforme o estímulo recebido. Em Conscious Acts of Creation temos igualmente a oportunidade de seguir uma série de experiências efectuadas em rigorosos contextos científicos em que, como já tivemos oportunidade de notar, sujeitos em meditação alteram o valor do ph, da concentração de iões e da condutividade da água. Exemplos como estes são seguidos de uma frase que se repete como um eco no filme What the \#\$!\%* Do We Know!? ${ }^{13}$ : "If thoughts can do this to water, imagine what they can do to humans!” sendo nós $85 \%$ água. Assim faz Mia Couto com Nãozinha:

Escute bem: em cada noite eu me converto em água, me trespasso em líquido. [...] Para dizer a verdade, eu só me sinto feliz quando me vou aguando. Nesse estado em que me durmo estou dispensada de sonhar: a àgua não tem passado. [...] [N]a àgua pode se bater sem causar ferida. Em mim, a vida pode golpear quando sou àgua. Pudesse eu para sempre residir em líquida matéria de espraiar, rio em estuário, mar infinito. Nem ruga, nem mágoa, toda curadinha do tempo. (COUTO, 1991, pp. 85-6)

Se integrarmos as duas perspectivas, podemos, além de ler esta metamorfose como um relato puramente fantástico de uma mulher que se diz bruxa, podemos também lê-la como uma capacidade elevadíssima de controle dos cinco agregados que dificilmente seríamos capazes de conceber para além de um nível puramente teórico. A verdade é que não existem nenhumas leis na física que expliquem os efeitos da consciência sobre o corpo humano, e este exemplo da escrita de Mia Couto é acima de tudo um exemplo do uso da tradição oral africana. O que nos interessa, no entanto, é a possibilidade de integração de ambas, de tal forma que ajude o leitor de língua inglesa a criar um vínculo com uma matéria que lhe é absolutamente estranha. A tradição oral africana e a física quântica parecem funcionar em dois polos distintos, não só espacialmente falando, mas também conceptualmente; porém, depois de se assistir ao filme What the $\# \$$ !\% Do We Know!?, a constatação colectiva, (tal como tive oportunidade de observar no contexto da sala de aula duma universidade norte-americana, com estudantes de língua inglesa) face a Under the Frangipani, é que há muito que a tradição africana responde às questões que uma muito recente ciência cognitiva e física quântica procuram ainda responder, mas é através desta que mais facilmente podemos traduzir a cultura de Under the Frangipani a um público leitor cujas referências são essencialmente objectivas e para quem A Varanda do Frangipani mais não é que uma espécie de Harry Potter. 


\section{REFERÊNCIAS BIBLIOGRÁFICAS}

ARNTZ, William, Betsy Chasse et al. (dir.) What the $\# \$ ! \%^{*}$ Do We Know!?, 2004.

COUTO, Mia. A Varanda do Frangipani. Lisboa: Caminho. 1991. Under the Frangipani. USA: The Serpent's Tail. 2001.

EMOTU, Masaru. The Hidden Messages in Water. USA: Beyond Words Publishing. 2004.

MARGULYS, Lynn, Dorian Sagan. What is Life? N.Y., London, Toronto, Sydney, Tokyo, Singapore: Simon \& Schuster. 1995.

MATURANA, H.R. , F. J. Varela. Autopoiesis and Cognition. Holland: D. Reidel Publishing Company. 1980.

MUTERE, Malaika. African Culture and Aesthetics. African Odyssey Arts \& Education Resources. The Kennedy Center African Odyssey Interactive. http://artsedge.kennedy-center.org/aoi/history/ao-guide. html\#culture

SCHRÖDINGER, Erwin. What is Life? The Physical Aspect of the Living Cell \& Mind and Matter. Cambridge: The University Press. 1967.

What is Life? The Physical Aspect of the Living Cell, Based on Lectures Delivered Under the Auspices of the Institute of Trinity College. Cambridge: The University Press. 1944.

TILLER, William, Walter Dibble, Michael Kohane. Conscious Acts of Creation: The Emergence of a New Physics. USA: Pavior Publishing. 2001.

VARELA, Francisco, Evan Thompson, and Eleanor Rosch. The Embodied Mind: Cognitive Science and Human Experience. Cambridge, MA: MIT Press. 1991.

WOLF, Fred A. "A Quantum Physics Model of the Timing of Consciousness Experience" in Hameroff, Stuart R, et al (ed.). Toward a Science of Consciousness III: The Third Tucson Discussions and Debates. Cambridge, Mass.; London, England: MIT Press. 1999.

(Recebido para publicação em 09/11/2011,

Aprovado em 10/12/2011)

\section{NOTAS}

1 Cita-se aleatoriamente o original e a tradução ao longo deste trabalho.

2 A física quântica trata-se de um larguíssimo corpus de estudo que não se tem a pretensão de abarcar aqui. As referências bibliográficas darão conta dos pontos que se desenvolvem com mais profundidade e apresentam-se uma série de notas de rodapé com referências online de molde a que o leitor menos especializado possa rapidamente desenvolver algumas ideias e encontrar outras fontes bibliográficas. 
3 Em 5/1/2004 o primeiro grupo de estudantes, possuindo um conhecimento razoável da língua portuguesa, procedeu a uma comparação da Varanda do Frangipani com Under the Frangipani, e concluiu que a incapacidade do tradutor de recriar as palavras inventadas por Couto impedia os leitores de seguirem a complexidade do seu pensamento e consequentemente criava uma história de enredo aparentemente simples e directo. $\mathrm{O}$ segundo grupo de estudantes escolheu como tema a morte/o aleitamento e as tensões culturais existentes na comunidade em causa. A fluidez da fronteira entre o mundo de Ermelindo e de Izidine simbolizaria a própria fluidez do texto escrito que deve ser ultrapassada de modo a alcançar a pluralidade significativa da obra. O terceiro grupo de estudantes vê a figura de Ermelindo como o centro da história sendo que a sua função é a de criar laços entre o leitor e a tradição moçambicana. Este grupo foca-se igualmente no simbolismo da natureza que pode indicar a vitória do bem sobre o mal. O quarto grupo de estudantes estabelece como o centro do seu trabalho a ligação entre o leitor e o Inspector. Segundo este grupo, o leitor encontra-se no mesmo estado de ignorância do Inspector; ainda para este grupo, a tradução de um mundo diferente prova-se como sendo a barreira mais difícil de ultrapassar, tal como Izidine não entende o mundo que o rodeia, assim se encontra o leitor. $\mathrm{O}$ quinto grupo discute o livro como sendo um ataque à civilização ocidental. $\mathrm{O}$ sexto grupo considera que o livro apresenta como tema recorrente o contra-estereótipo de brancos versus negros. Finalmente, o sétimo grupo demonstra como os temas do ciclo do tempo e da ligação entre a morte e a vida ocorrem ao longo da narrativa.

4 Existe um glossário de termos na edição em português, de todo ausente da edição em inglês, como se não valesse a pena elucidar o leitor que o "halavakuma" ou o pangolim é uma entidade que em "todo o Moçambique se acredita que [...] habita os céus, descendo à terra para transmitir aos chefes tradicionais as novidades sobre o futuro." (COUTO, 1991, p. 153).

5 Para o desenvolvimento complexo e minucioso do assunto, cf. De Broglie, Louis. The Current Interpretation of Wave Mechanics, a Critical Study. Amsterdam, New York: Elsevier Pub. Co.. 1964.

6 Cf. http://www.aip.org/history/heisenberg/p08.htm

7 Cf. http://plato.stanford.edu/entries/qm-copenhagen/

8 Cf. http://plato.stanford.edu/entries/berkeley/

9 http://plato.stanford.edu/entries/qm-manyworlds/

10 Cf. http://www.mtnmath.com/cat.html

11 Cf. http://www.mtnmath.com/faq/meas-qm-3.html para uma explicação básica desta experimentação e para o levantamento de outras dúvidas, prossiga com http://www. heaven-words.com/3.htm e http://www.higgo.com/quantum/laymans.htm

12 Cf. tillerfoundation.com/ConActsCreation.pdf para introdução ao texto; cf. também o vídeo "Conscious Acts of Creation”, 2005.

13 Cf. www.whatthebleep.com/ para resumo do filme e informações várias sobre o mesmo. 